\title{
Implementasi Newton Raphson Termodifikasi pada Prediksi Distribusi Tekanan Pipa Transmisi Gas Alam
}

\author{
Annisa Aditsania \#1, Isman Kurniawan \#2 \\ \# School of Computing, Telkom University \\ telkom street no.1 Bandung, Indonesia \\ ${ }^{1}$ aaditsania@telkomuniversity.ac.id \\ ${ }^{2}$ ismankrn@telkomuniversity.ac.id
}

\begin{abstract}
Profile prediction of pressure distribution along the transmission pipeline network is one of important procedures to evaluate the performance of pipeline network design. In this research, the pressure distribution for each pipe is modeled as a function of fluid properties, segment's pipe properties, and the environment of pipeline network by Panhandle A correlation. Panhandle A correlation can be considered as non-linear equation. In the previous research, Newton Raphson method is used as a method to get numeric solution due to its high convergence order. In this research, for optimum computing time of network distribution calculation, the modified Newton Raphson method is chosen as a method for finding the numeric solution. The simulation result shows that the pressure distribution profile using modified Newton Raphson method is accurate with $0.28 \%$ maximum relative error compared with field data.
\end{abstract}

Keywords: pressure drop, temperature drop, transmission pipeline, modified Newton Raphson

\begin{abstract}
Abstrak
Prediksi profil distribusi tekanan disepanjang jaringan pipa transmisi merupakan salah satu prosedur penting untuk mengevaluasi performa desain jaringan pipa. Pada penelitian ini, distribusi tekanan untuk setiap segmen pipa dimodelkan menggunakan korelasi Panhandle A sebagai fungsi dari properti fluida, properti segmen pipa dan properti lingkungan jaringan pipa. Korelasi Panhandle A secara matematis dapat dipandang sebagai persamaan non-linear. Pada penelitian-penelitian terdahulu, metode Newton Raphson dipilih sebagai metode untuk mendapatkan solusi numerik, karena orde konvergensi tinggi. Sebagai upaya untuk mengoptimalkan waktu komputasi dari perhitungan distribusi jaringan, pada penelitian kali ini, metode Newton Raphson termodifikasi dipilih sebagai metode pencarian solusi numerik. Hasil simulasi menunjukan bahwa profil distribusi tekanan menggunakan metode Newton Raphson termodifikasi akurat dengan error relatif maksimum $0.28 \%$ untuk batas toleransi error $10^{-5}$ bila dibandingkan dengan profile distribusi tekanan data lapangan
\end{abstract}

Kata Kunci: penurunan tekanan, penurunan temperatur, pipa transmission, Newton Raphson termodifikasi 


\section{PENDAhUluan}

CEKTOR perminyakan dan gas adalah sektor yang memegang kendali besar di Indonesia. Sektor ini S berkontribusi pada pendapatan Negara (sumber 12\% APBN) dan juga berkontribusi untuk meningkatkan pertumbuhan ekonomi masyarakat[1]. Salah satu kendala Indonesia untuk mengoptimalkan potensi ini adalah kebutuhan dan pasokan gas tersebar tidak merata. Ada berbagai jenis moda transportasi gas, seperti CNG, LPG dan pipa transmisi.

Penelitian terkait pipa transmisi gas alam termasuk penelitian yang sudah cukup tua. Penelitian tentang perilaku aliran gas dalam pipa sudah dimulai sejak sekitar 1969. Stoner melakukan penelitian tentang aliran gas pada kondisi steady state di sistem jaringan distribusi gas. Model yang dibangun oleh Stoner merupakan hasil substitusi persamaan korelasi gas ke model kesetimbangan aliran. Hasil substitusi tersebut merupakan sistem besar persamaan non-linear[2]. Pada tahun 2004, Kuntjoro dkk mengusulkan metode perhitungan untuk mencari solusi model yang telah dibangun oleh Stoner. Pada penelitiannya, metode algoritma genetik yang dilengkapi clearing procedure dari Perowski dipilih sebagai metode untuk menentukan akar sistem persamaan nonlinear[3]

Penelitian mengenai model aliran gas untuk pipa transmisi gas alam ini ditahun 2011 kembali dikembangkan oleh Abraham Debebe dan Mohd Amin. Pada penelitian tersebut, pipa transmisi dimodelkan berdasar pada prinsip-prinsip aliran gas melalui pipa, kesetimbangan massa dan karakteristik kompresor. Metode NewtonRaphson merupakan metode yang diusung Abraham Debebe dan Mohd Amin untuk mencari solusi persamaan sistem[4].

Penelitian kali ini, bertujuan menggabungkan dan mengembangkan metode-metode perhitungan profil tekanan di pipa transmisi. Pipa yang ditinjau pada penelitian ini adalah pipa berbentuk jaringan dengan perubahan sudut elevasi dan temperatur di setiap segmen pipa. Diameter dari pipa jaringan ini tergolong berukuran sedang-besar (12-60 inchi). Oleh karena itu, korelasi aliran gas yang paling sesuai adalah Panhandle A[5]. Dari segi metode, metode numerik dipilih sebagai metode pencarian solusi, karena persamaan aliran gas terdiri atas rangkaian korelasi-korelasi parameter gas lainnya yang tidak dapat diabaikan[6]. Solusi numerik persamaan tekanan pada penelitan terdahulu umumnya diselesaikan menggunakan metode Newton-Raphson. Sedangkan pada penelitian ini, metode Newton-Raphson termodifikasi digunakan untuk mencari solusi persamaan non-linear penurunan tekanan. Newton Raphson termodifikasi merupakan salah satu metode yang telah berhasil meningkatkan konvergensi metode Newton Raphson menjadi orde $1+\sqrt{2} \approx 2.4$ [7]. Tujuan dari penelitian ini adalah memberikan gambaran distribusi aliran tekanan gas sepanjang pipa transmisi dengan proses komputasi yang optimal. Dengan gambaran distribusi tekanan disepanjang pipa, diharapkan evaluasi performansi jaringan pipa transmisipun dapat dilakukan secara akurat dan presisi.

\section{METODOLOGI}

Saat gas dialirkan dalam pipa salur transmisi, tekanan disepanjang pipa mengalami penurunan. Banyak faktor yang mempengaruhi penurunan tekanan, seperti: jenis gas, bentuk pipa, laju alir gas, temperatur pipa, bentuk jaringan pipa. Pada penelitian ini, profil distribusi tekanan didapatkan setelah melalui beberapa tahapan. Secara umum, langkah-langkah yang dilakukan dalam penelitian ini dapat dilihat pada Gambar 1 .

\section{A. Meng-inputkan properti gas dan pipa.}

Pada penelitian kali ini, sistem diujikan pada pipa dengan beberapa perubahan elevasi yang dialiri gas dengan laju alir dan specific gravity tertentu. Selain elevasi dari masing-masing segmen pipa, properti pipa lainnya seperti: jenis node inlet, tekanan outlet, temperatur inlet, temperatur lingkungan, panjang pipa, diameter dalam pipa, tebal dinding pipa, efisiensi, dan roughness merupakan inputan sistem ini. 


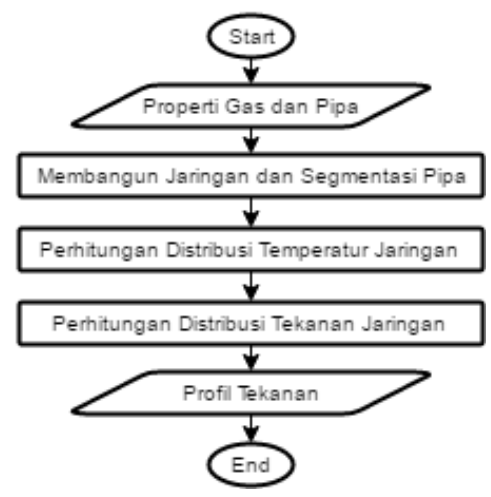

Gambar 1. Alur Umum Sistem

\section{B. Membangun jaringan dan segmentasi pipa}

Jaringan pipa transmisi adalah pipa yang saling terhubung dan dapat mentransportasikan gas dari sistem pengumpul (sumber gas) ke outlet gas (sink). Data yang digunakan sebagai input pada penelitian ini adalah data pipa dan gas. Masing-masing pipa mengalirkan gas dengan arah alir gas yang berbeda. Oleh karena itu, untuk membangun sebuah sistem alir yang kontinu, pipa harus dikolaborasikan. Pada penelitian kali ini, metode Depth First Search dipilih sebagai algoritma penelusuran struktur. Setelah arah aliran gas berhasil disusun, karakteristik gas di titik temu antar pipa harus dapat ditentukan. Karakteristik gas pada titik temu pipa merupakan kombinasi gas inlet pipa yang terkait.

Menurut [8], karakteristik gas yang mengalir pada titik temu merajuk pada keseimbangan aliran gas dalam jaringan pipa tersebut. Ilustrasi dari penentuan karakteristik gas pada titik temu ditampilkan pada Gambar 2

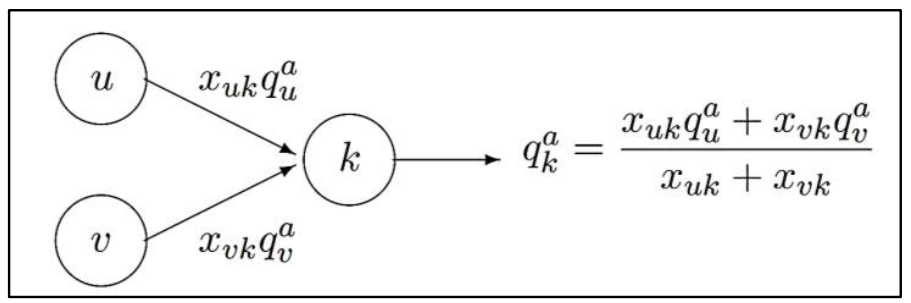

Gambar 2. Kombinasi Karakteristik Gas pada Titik Temu.

Pada umumnya, pipa penyusun jaringan pipa transmisi di lapangan tidak berada dalam kondisi horizontal. Aliran tekanan dan temperatur disepanjang pipa dipengaruhi juga oleh elevasi pipa. Oleh karena itu, pipa akan disegmentasi berdasarkan perbedaan elevasinya. Misalkan diketahui pipa transmisi seperti pada Gambar 3:

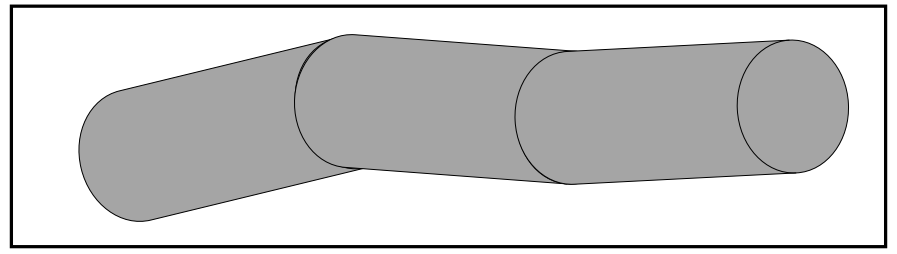

Gambar 3. Ilustrasi Pipa dengan sudut elevasi

Jika diasumsikan elevasi adalah jarak yang dibentuk pipa dengan dari garis horizontal acuan, maka terdapat 3 perubahan elevasi pada pipa Gambar.3. Oleh karena itu, pipa pada Gambar.3 akan disegmentasi menjadi 3 bagian. 
Annisa Aditsania et.al.

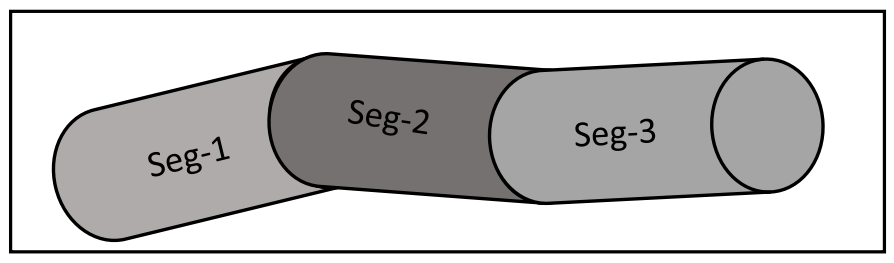

Gambar 4. Segmentasi Pipa berelevasi

Aliran gas dalam pipa bersifat kontinu maka gas yang keluar pada pada segmen- $i$ akan menjadi masukan gas segmen- $i+1$. Sebagai contoh, keluaran gas segmen-1 akan menjadi masukan gas di segmen-2 dan berlaku untuk segmen seterusnya.

C. Perhitungan distribusi temperatur sepanjang pipa menggunakan model Michael A Hein.

Pada penelitian-penelitian sebelumnya, simulasi yang dilakukan adalah simulasi prediksi tekanan disepanjang pipa dengan mengasumsikan temperatur disepanjang pipa konstan (isothermal). Jika asumsi tersebut digunakan, maka masing-masing titik temperatur di setiap segment akan diisi dengan nilai temperatur inlet. Sedangkan pada penelitian kali ini, perhitungan prediksi tekanan dilakukan tanpa mengabaikan perubahan temperatur, maka penurunan tekanan di setiap segmen dari inlet ke outlet perlu dihitung terlebih dahulu.

Jika arah laju alir gas $(Q)$ dan temperatur di suatu titik pipa diketahui maka temperatur di titik lain segmen tersebut menurut Manning(1991), dengan menggunakan model Hein(1984), dapat dihitung menggunakan persamaan berikut[9]:

$$
T_{\text {out }}=\left(T_{\text {in }}-T_{s}-\theta\right) e^{-\beta L}+\left(T_{s}+\theta\right)
$$

dengan

$$
\begin{gathered}
\theta=\frac{\eta\left(P_{\text {out }}-P_{\text {in }}\right)}{\beta L}+\frac{\left(\text { Elevasi }_{\text {in }}-\text { Elevasi }_{\text {out }}\right)}{\left(778 C_{p} \beta L\right)} \\
\beta=1.467 \frac{U \times A}{m \times C_{p}} \\
m=\frac{q_{g} \times M W}{379.5 \times 24 \times 3,600}
\end{gathered}
$$

Pada penelitian kali ini efek Joule-Thomson diabaikan. Oleh karena itu, koefisien Joule Thomson $(\eta)$, bernilai 0.

\section{Perhitungan distribusi tekanan sepanjang pipa menggunakan model Panhandle A.}

Panhandle A memformulasikan tekanan disisi satu sebagai fungsi dari laju alir, efisiensi, diameter dalam pipa, specific gravity gas, temperatur, panjang pipa, elevasi, tekanan disisi lainnya dan komprebilitas z-Faktor. Berikut adalah bentuk umum dari penurunan tekanan jika diketahui tekanan di outlet [10]:

$$
P_{\text {in }}=\left[\left(\frac{q_{g}}{435.87 \times E \times I D_{\text {pipe }}^{2.618}}\right)^{1.854} \times\left(\frac{P_{\text {base }}}{T_{\text {base }}}\right)^{2} \times S G g^{0.854} \times T_{\text {ave }} \times L_{e q} \times Z+e^{s_{\text {elev }}} \times P_{\text {out }}^{2}\right]^{0.5}
$$

dengan

$$
T_{\text {ave }}=\frac{2}{3}\left[\left(T_{\text {in }}+T_{\text {out }}\right)-\frac{\left(T_{\text {in }} \times T_{\text {out }}\right)}{\left(T_{\text {in }}+T_{\text {out }}\right)}\right]
$$




$$
\begin{aligned}
& L_{e q}=\frac{L_{\text {segment }} \times\left(e^{S_{\text {elev }}}-1\right)}{S_{\text {elev }}}, \\
& L_{\text {segment }}=\frac{\text { Elevation }_{\text {out }}-\text { Elevation }_{\text {in }}}{\operatorname{Sin}(\theta)}, \\
& S_{\text {elev }}=\frac{0.0375 \gamma_{g}\left(\text { Elevation }_{\text {out }}-\text { Elevation }_{\text {in }}\right)}{T_{\text {ave }} Z} . \\
& Z=\frac{1}{\left(1+\frac{\text { Pave } 34440010^{1.785 S G g}}{T^{3.825}}\right)} \\
& P_{\text {ave }}=\frac{2}{3}\left(P_{\text {in }}+P_{\text {out }}-\frac{P_{\text {in }} \times P_{\text {out }}}{P_{\text {in }}+P_{\text {out }}}\right)
\end{aligned}
$$

Komprebilitas Z-Faktor $(Z)$ adalah properti gas yang digunakan untuk memodifikasi persamaan gas ideal. Dalam penelitian ini, persamaan CNGA digunakan untuk memodelkan kompresibilitas z-Faktor. CNGA memformulasikan komprebilitas z-Faktor sebagai fungsi dari perbandingan temperatur gas dengan temperatur kritis dan perbandingan tekanan gas dengan tekanan kritis.

Persamaan tekanan yang dihasilkan oleh Panhandle A berbentuk persamaan non-linear yang cukup rumit. Metode Newton Raphson termodifikasi dipilih sebagai metode untuk pencarian solusi pada persamaan tersebut. Metode Newton Raphson termodifikasi memperbaiki nilai solusi mulai dari iterasi ke 2. Solusi persamaan pada iterasi ke-2 $\left(x_{2}\right)$ dihitung menggunakan solusi numerik iterasi ke-1 $\left(x_{1}\right)$, nilai fungsi yang telah disubstitusikan solusi numerik iterasi-1 $\left(f\left(x_{1}\right)\right)$, dan turunan fungsi yang sudah terlebih dahulu di evaluasi di titik $\frac{1}{2}\left(x_{1}+x_{1}^{*}\right)$. Berikut adalah algoritma dari metode Newton Raphson termodifikasi

INPUT: tebakan awal $x_{0}$, batas toleransi TOL, maksimum iterasi $N_{0}$

OUTPUT: approksimasi akar $x$ atau pesan "akar belum ditemukan"

Step 1. Set $i=1$

Set $x_{0}^{*}=x_{0}$

Set $x_{1}=x_{0}-f\left(x_{0}\right) / f^{\prime}\left(\frac{1}{2}\left[x_{0}+x_{0}^{*}\right]\right)$

Step 2. While $i \leq N_{0}$ do Step 3-5

$$
\begin{aligned}
& \text { Step 3. Set } x_{i}^{*}=x_{i}-f\left(x_{i}\right) / f^{\prime}\left(\frac{1}{2}\left[x_{i-1}+x_{i-1}^{*}\right]\right) \\
& \text { Set } x_{i+1}=x_{i}-f\left(x_{i}\right) / f^{\prime}\left(\frac{1}{2}\left[x_{i}+x_{i}^{*}\right]\right) \\
& \text { Step 4. If }\left|x_{i+1}-x_{i}\right|<\text { TOL then } \\
& \text { OUTPUT }\left(x_{i+1}\right) \\
& \text { STOP }
\end{aligned}
$$

Step 5. Set $i=i+1$

Step 6. OUTPUT (“Akar belum ditemukan setelah $N_{0}$ iterasi”) STOP

\section{IMPLEMENTASI DAN ANALISIS SISTEM}

Data gas alir pipa yang digunakan pada penelitian ini adalah data gas alir pada pipa lapangan yang terdiri atas 7 buah pipa, 4 sumber gas, dan 1 buah sink. Setiap pipa disertai properti bentuk pipa dan inlet node dan outlet 
Annisa Aditsania et.al.

IMPLEMENTASI NEWTON RAPHSON TERMODIFIKASI PADA...

node pipa. Dari infomasi tersebut, objek seperti pipa, sumber gas dan sink dapat dibangun menjadi sebuah jaringan seperti Gambar 5.

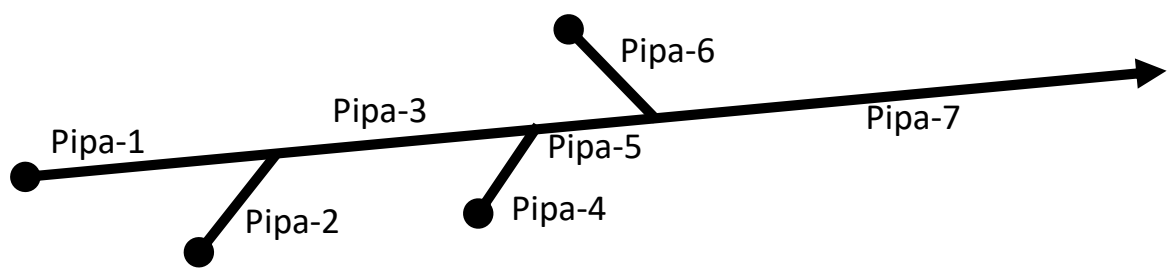

Gambar 5. Jaringan Pipa Transmisi Gas

Ada beberapa jenis node pada jaringan pipa transmisi, diantaranya node sumber gas, node titik temu dan node sink. Perhitungan distribusi tekanan di pipa bergantung dengan jenis node awal dan node akhir pipa tersebut. Hal inilah, yang mendorong penggunaan Depth First Search pada penelitian ini. Gambar 6 menampilkan jaringan hasil pengelompokan dan pengurutan untuk perhitungan distribusi tekanan.

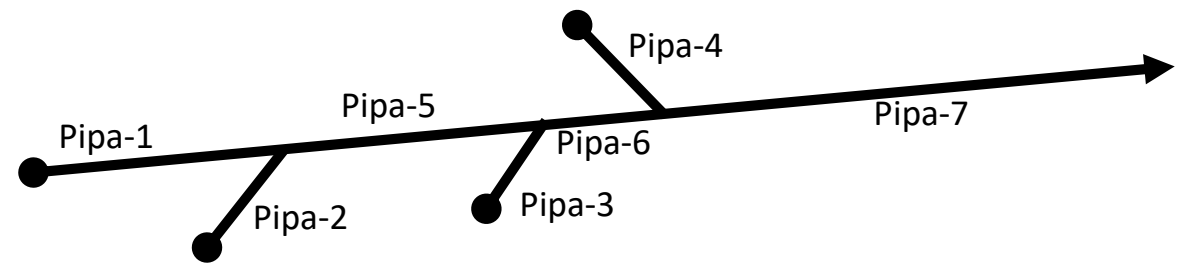

Gambar 6. Jaringan Pipa Transmisi Gas Terurut

Pada penelitian ini, setiap sumber gas memberikan informasi temperatur awal, besar laju alir gas, dan besaran spesifik gas gravity. Sedangkan, informasi yang diberikan oleh node sink hanyalah tekanan di titik akhir salah satu pipa. Masing-masing pipa mengalirkan gas dengan arah alir gas yang berbeda. Selain arah alir gas yang berbeda, pipa juga memiliki segmentasi-segmentasi yang menjadikan pipa tersebut unik. Tabel I menampilkan hasil simulasi distribusi tekanan setiap segmen di sepanjang jaringan pipa yang terdiri atas 7 pipa dengan batas toleransi error setiap segmen $10^{-5}$.

TABEL I

DISTRIBUSI TEKANAN DI JARINGAN PIPA

\begin{tabular}{|c|c|c|c|c|c|}
\hline \multirow{2}{*}{ No } & \multirow{2}{*}{ Segment } & \multicolumn{2}{|c|}{$\begin{array}{c}\text { Volume Flow Rate } \\
\text { (MMSCFD) }\end{array}$} & \multicolumn{2}{c|}{ Pressure (psig) } \\
\cline { 3 - 6 } & & Inlet & Outlet & Inlet & Outlet \\
\hline \multirow{2}{*}{$\begin{array}{c}\text { Pipa } \\
1\end{array}$} & Seg1-1 & 162.2606 & 162.2606 & $1,480.23$ & $1,490.18$ \\
\cline { 2 - 6 } & Seg1-2 & 162.2606 & 162.2606 & $1,490.18$ & $1,478.52$ \\
\hline \multirow{4}{*}{$\begin{array}{c}\text { Pipa } \\
2\end{array}$} & Seg2-1 & 43.2298 & 43.2298 & $1,469.01$ & $1,478.27$ \\
\cline { 2 - 6 } & Seg2-2 & 43.2298 & 43.2298 & $1,478.27$ & $1,478.78$ \\
\cline { 2 - 6 } & Seg2-3 & 43.2298 & 43.2298 & $1,478.78$ & $1,478.68$ \\
\cline { 2 - 6 } & Seg2-4 & 43.2298 & 43.2298 & $1,478.68$ & $1,478.39$ \\
\cline { 2 - 6 } & Seg2-5 & 43.2298 & 43.2298 & $1,478.39$ & $1,478.52$ \\
\hline \multirow{4}{*}{$\begin{array}{c}\text { Pipa } \\
\text { 3 }\end{array}$} & Seg3-1 & 205.4904 & 205.4904 & $1,478.52$ & $1,476.35$ \\
\cline { 2 - 6 } & Seg3-2 & 205.4904 & 205.4904 & $1,476.35$ & $1,475.75$ \\
\cline { 2 - 6 } & Seg3-3 & 205.4904 & 205.4904 & $1,475.75$ & $1,472.03$ \\
\hline
\end{tabular}

\begin{tabular}{|c|c|c|c|c|c|}
\hline \multirow{4}{*}{ No } & \multirow{2}{*}{ Segment } & \multicolumn{2}{|c|}{$\begin{array}{c}\text { Volume Flow Rate } \\
\text { (MMSCFD) }\end{array}$} & \multicolumn{2}{c|}{ Pressure (psig) } \\
\cline { 3 - 6 } & & Inlet & Outlet & Inlet & Outlet \\
\hline \multirow{4}{*}{$\begin{array}{c}\text { Pipa } \\
\text { 6 }\end{array}$} & Seg6-1 & 144.5906 & 144.5906 & $1,388.18$ & $1,401.19$ \\
\cline { 2 - 6 } & Seg6-2 & 144.5906 & 144.5906 & $1,401.19$ & $1,382.24$ \\
\hline \multirow{4}{*}{\begin{tabular}{c} 
Pipa \\
\cline { 2 - 6 }
\end{tabular}} & Seg7-1 & 385.9786 & 385.9786 & $1,382.24$ & $1,321.80$ \\
\cline { 2 - 6 } & Seg7-2 & 385.9786 & 385.9786 & $1,321.80$ & $1,307.29$ \\
\cline { 2 - 6 } & Seg7-3 & 385.9786 & 385.9786 & $1,307.29$ & $1,261.79$ \\
\cline { 2 - 6 } & Seg7-4 & 385.9786 & 385.9786 & $1,261.79$ & $1,172.25$ \\
\cline { 2 - 6 } & Seg7-5 & 385.9786 & 385.9786 & $1,172.25$ & $1,170.44$ \\
\cline { 2 - 6 } & $\vdots$ & $\vdots$ & $\vdots$ & $\vdots$ & $\vdots$ \\
\cline { 2 - 6 } & Seg7-11 & 385.9786 & 385.9786 & $1,026.67$ & $1,025.25$ \\
\cline { 2 - 6 } & Seg7-12 & 385.9786 & 385.9786 & $1,025.25$ & $1,003.55$ \\
\hline
\end{tabular}




\begin{tabular}{|c|c|c|c|c|c|} 
Pipa & Seg4-1 & 35.8976 & 35.8976 & $1,473.03$ & $1,487.05$ \\
\cline { 2 - 6 } 4 & Seg4-2 & 35.8976 & 35.8976 & $1,487.05$ & $1,472.03$ \\
\hline \multirow{4}{*}{$\begin{array}{c}\text { Pipa } \\
5\end{array}$} & Seg5-1 & 241.388 & 241.388 & $1,472.03$ & $1,470.08$ \\
\cline { 2 - 6 } & Seg5-2 & 241.388 & 241.388 & $1,470.08$ & $1,468.26$ \\
\cline { 2 - 6 } & Seg5-3 & 241.388 & 241.388 & $1,468.26$ & $1,451.70$ \\
\cline { 2 - 6 } & $\vdots$ & $\vdots$ & $\vdots$ & $\vdots$ & $\vdots$ \\
\cline { 2 - 6 } & Seg5-17 & 241.388 & 241.388 & $1,395.64$ & $1,394.82$ \\
\cline { 2 - 6 } & Seg5-18 & 241.388 & 241.388 & $1,394.82$ & $1,382.24$ \\
\hline
\end{tabular}

\begin{tabular}{|c|c|c|c|c|} 
Seg7-13 & 385.9786 & 385.9786 & $1,003.55$ & $1,002.11$ \\
\hline Seg7-14 & 385.9786 & 385.9786 & $1,002.11$ & 984.19 \\
\hline Seg7-15 & 385.9786 & 385.9786 & 984.19 & 980.93 \\
\hline Seg7-16 & 385.9786 & 385.9786 & 980.93 & 980.63 \\
\hline Seg7-17 & 385.9786 & 385.9786 & 980.63 & 974.92 \\
\hline Seg7-18 & 385.9786 & 385.9786 & 974.92 & 973.29 \\
\hline Seg7-19 & 385.9786 & 385.9786 & 973.29 & 966.09 \\
\hline Seg7-20 & 385.9786 & 385.9786 & 966.09 & 953.77 \\
\hline
\end{tabular}

Untuk mengukur keakuratan prediksi yang didapat, tekanan pada titik sumber gas hasil dari simulasi akan dibandingakan dengan data lapangan tekanan titik sumber gas. Tabel II menampilkan error relatif untuk masingmasing titik sumber gas.

TABEL II

VALIDASI DATA

\begin{tabular}{|c|c|c|c|}
\hline Node & $\begin{array}{c}\text { Data } \\
\text { Tekanan } \\
\text { Hasil } \\
\text { Simulasi } \\
\text { Lapangan } \\
\text { Tekanan }\end{array}$ & $\begin{array}{c}\text { Error } \\
\text { Relatif }\end{array}$ \\
\hline Source 1 & 1480.2334 & 1476.17 & 0.002753 \\
\hline Source 2 & 1469.0125 & 1473.18 & 0.002829 \\
\hline Source 3 & 1473.0340 & 1472.75 & 0.000193 \\
\hline Source 4 & 1388.1776 & 1387 & 0.000849 \\
\hline \multicolumn{3}{|c|}{ Rataan (MAPE) } & 0.001656 \\
\hline
\end{tabular}

Tabel II menunjukan sumber gas 1 dan sumber gas 2 menghasilkan error yang lebih besar bila dibandingkan dengan sumber gas 3 dan 4. Bila diamati lebih lanjut, error ini timbul karena letak dari sumber gas 1 dan sumber gas 2 yang relatif lebih jauh, bila dibandingkan dengan sumber gas 3 dan 4, dari sink.

Perhitungan tekanan dilakukan secara mundur dari sink ke sumber gas yang dihubungkan oleh jaringan pipa. Oleh karena itu, semakin jauh posisi sumber gas dari sink maka error yang terhitung pada sumber gas tersebut akan semakin besar akibat error kumulatif segmen-segmen sebelumnya.

Partisi dalam segmen dapat meningkatkan akurasi dari solusi numerik yang diberikan. Tabel III menampilkan error relatif bergantung pada jumlah partisi dan jumlah iterasinya

TABEL III

AKURASI VS JUMLAH ITERASI

\begin{tabular}{|c|c|c|c|c|}
\hline & \multicolumn{4}{|c|}{ error relatif } \\
\cline { 2 - 5 } & 1 partisi & 5 partisi & 10 partisi & $\begin{array}{c}50 \\
\text { partisi }\end{array}$ \\
\hline Source 1 & 0.275269 & 0.271867 & 0.27176 & 0.27173 \\
\hline Source 2 & 0.282888 & 0.284974 & 0.28504 & 0.28506 \\
\hline Source 3 & 0.01928 & 0.009751 & 0.009434 & 0.00933 \\
\hline Source 4 & 0.084904 & 0.083026 & 0.082967 & 0.08295 \\
\hline
\end{tabular}


Annisa Aditsania et.al.

IMPLEMENTASI NEWTON RAPHSON TERMODIFIKASI PADA...

\begin{tabular}{|l|l|l|l|l|} 
Total Iterasi & 171 & 780 & 1560 & 7749 \\
\hline
\end{tabular}

Tabel III menunjukan bahwa meningkatkan akurasi dengan menambah jumlah partisi berdampak pada meningkatnya total iterasi. Namun, bila total iterasi pada masing-masing kolom dibagi dengan jumlah partisi kolomnya maka jumlah iterasi per-segmen pipa dapat ditentukan. Tabel IV menunjukan jumlah iterasi persegmen untuk setiap simulasi ragam partisi

TABEL IV

ITERASI PER SEGMEN PIPA

\begin{tabular}{|c|c|c|c|c|}
\hline & 1 partisi & 5 partisi & 10 partisi & $\begin{array}{c}50 \\
\text { partisi }\end{array}$ \\
\hline Total Iterasi & 171 & 780 & 1560 & 7749 \\
\hline $\begin{array}{c}\text { Jumlah Iterasi/ } \\
\text { Segmen }\end{array}$ & 171 & 156 & 156 & 154.98 \\
\hline
\end{tabular}

\section{KESIMPULAN}

Prediksi tekanan pada jaringan pipa transmisi gas menghasilkan nilai yang akurat dengan error relatif maksimum $0.28 \%$ untuk batas toleransi error $10^{-5}$. Semakin besar jarak antara sink dengan sumber gas, maka error relatif akan semakin membesar. Membagi segmen pipa menjadi beberapa partisi kecil meningkatkan akurasi perhitungan. Total iterasi yang membludak ketika meningkatkan jumlah partisi segmen diakibatkan oleh pengali partisi. Bila ditinjau dari segmentasi pipa, meningkatkan jumlah partisi juga berdampak pada penurunan jumlah iterasi segmen.

\section{NOMENCLATURE}

\begin{tabular}{|l|l|c|l|}
\hline No. & \multicolumn{1}{|c|}{ Parameter } & Simbol & \multicolumn{1}{c|}{ Unit } \\
\hline 1. & Inlet Pressure & $P_{\text {in }}$ & Psia \\
\hline 2. & Outlet Pressure & $P_{\text {out }}$ & Psia \\
\hline 3. & Average Pressure & $P_{\text {ave }}$ & Psia \\
\hline 4. & Inlet Temperature & $T_{\text {in }}$ & $\mathrm{F}$ \\
\hline 5. & Outlet Temperature & $T_{\text {out }}$ & $\mathrm{F}$ \\
\hline 6. & Average Temperature & $T_{\text {ave }}$ & $\mathrm{F}$ \\
\hline 7. & T surrounding & $T_{S}$ & $\mathrm{~F}$ \\
\hline 8. & Flow Rate & $q_{g}$ & MMSCFD \\
\hline 9. & Specific Gravity Gas & SGg & Dimensionless \\
\hline 10. & Length of Segment & $L_{\text {segment }}$ & Miles \\
\hline 11. & Inside Diameter & $I D_{\text {pipe }}$ & In \\
\hline 12. & Pipeline Efficiency & $E$ & Fraction \\
\hline
\end{tabular}

UCAPAN TERIMAKASIH

Untuk seluruh pihak yang telah membantu penyelesaian penelitian ini: Dr. Darmadi Soetikno, Dila Puspita, Kaisa Putri, Aisyah Putri

\section{DAFTAR PUSTAKA}

[1] Widodo Wahyu Purwanto, Yuswan Muharam, Yoga Wienda Pratama, Djoni Hartono, Harimanto Soedirman, Rezki Anindhito, Status and outlook of natural gas industry development in Indonesia, Journal of Natural Gas Science and Engineering, Volume 29, February 2016, Pages 55-65, ISSN 1875-5100, 
[2] M.A Stoner, "Steady-State Analysis of Gas Production, Transmission and Distribution System", paper SPE 2554 presented at the SPE 44 ${ }^{\text {th }}$ Annual Fall Meeting, Denver, Colo., Sept. 28-Oct. 1, 1969.

[3] Sidarto K.A., Saiman dan N. Rohani. 2004. Menentukan Akar Sistem Persamaan Tak Linier dengan Memanfaatkan Algoritma Genetika yang Dilengkapi Clearing Procedure dari Petrowski. In Proceedings of Konferensi Nasional Matematika XII (Denpasar, Bali, 23-27 Juli, 2004).

[4] A.D. Woldeyohannes, M. A. A Majid, "Simulation Model for Natural Gas Transmission Pipeline Network System", Journal of Simulation Modelling Practice and Theory(January 2011), pp196-212

[5] Endorsements for the Second Edition, In Handbook of Natural Gas Transmission and Processing (Second Edition), edited by Saeid Mokhatab and William A. Poe, Gulf Professional Publishing, Boston, 2012, Pages i-ii, ISBN 9780123869142, http://dx.doi.org/10.1016/B978-0-12-386914-2.00029-7.

[6] Farzad Abdolahi, Ali Mesbah, Ramin B. Boozarjomehry, William Y. Svrcek, The effect of major parameters on simulation results of gas pipelines, International Journal of Mechanical Sciences, Volume 49, Issue 8, August 2007, Pages 989-1000, ISSN 0020-7403, http://dx.doi.org/10.1016/j.ijmecsci.2006.12.001.

[7] Trevor J. McDougall, Simon J. Wotherspoon, A simple modification of Newton's method to achieve convergence of order, Applied Mathematics Letters, Volume 29, March 2014, Pages 20-25, ISSN 0893-9659,

[8] Roger Z. Ríos-Mercado, Conrado Borraz-Sánchez, Optimization problems in natural gas transportation systems: A state-of-the-art review, Applied Energy, Volume 147, 1 June 2015, Pages 536-555, ISSN 0306-2619, http://dx.doi.org/10.1016/j.apenergy.2015.03.017.

[9] Manning, Francis S. Oilfield Processing of Petroleum, PennWell Publishing Co., Tulsa, 1991

[10] Shashi Menon, Gas Pipeline Hydraulics, Taylor \& Francis Group, Boca Raton, 2005 
